2. Mery CM, De León LE, Trujillo-Diaz D, Ocampo EC, Dickerson HA, Zhu H, et al. Contemporary outcomes of the Fontan operation: a large single-institution cohort. Ann Thorac Surg. 2019;105:1439-46.

3. Mori M, Aguirre AJ, Elder RW, Kashkouli A, Farris AB, Ford RM, et al. Beyond a broken heart: circulatory dysfunction in the failing Fontan. Pediatr Cardiol. 2014; 35:569-79.

4. Chaudhari M, Sturman J, O'Sullivan J, Smith J, Wrightson N, Parry G, et al. Rescue cardiac transplantation for early failure of the Fontan-type circulation in children. $J$ Thorac Cardiovasc Surg. 2005; 129:416-22.

5. Rychik J, Atz AM, Celermajer DS, Deal BJ, Gatzoulis MA, Gewillig MH, et al. Evaluation and management of the child and adult with Fontan circulation: a scientific statement from the American Heart Association. Circulation. 2019;140:e234-84.

6. Salazar JD, Zafar F, Siddiqui K, Coleman RD, Morales DLS, Heinle JS, et al. Fenestration during Fontan palliation: now the exception instead of the rule. J Thorac Cardiovasc Surg. 2010;140:129-36.
See Article page 1426

\section{Commentary: If only we knew when we would fail}

\author{
Manan H. Desai, MD, and Can Yerebakan, MD
}

Approximately 5 decades ago, Fontan and colleagues ${ }^{1}$ gave a new lease on life to patients with single ventricle physiology by introducing a novel surgical procedure. Soon after the total cavopulmonary connection (TCPC) surgery was designed, it was realized that patient selection was critical for the success of the procedure; thus, the commandments of the Fontan procedure were introduced. ${ }^{2}$ As the procedure underwent several modifications and perioperative management improved, contraindications of the procedure were liberalized.

In this issue of the Journal, Quaila and colleagues ${ }^{4}$ have tried to address the problem of predicting early Fontan failure. They retrospectively reviewed the imaging and clinical data of 131 patients who had undergone total cavopulmonary circulation. In the first part of the study, they created and validated a formula to predict postoperative hemodynamic data using preoperative cardiac magnetic resonance (CMR) imaging. The calculated post-TCPC central venous pressure (CVP) correlated well with the

\footnotetext{
From the Department of Cardiovascular Surgery, Children's National Heart Institute, Children's National Hospital, The George Washington University School of Medicine and Health Sciences, Washington, DC.

Disclosures: The authors reported no conflicts of interest.

The Journal policy requires editors and reviewers to disclose conflicts of interest and to decline handling or reviewing manuscripts for which they may have a conflict of interest. The editors and reviewers of this article have no conflicts of interest.

Received for publication July 18, 2020; revisions received July 18, 2020; accepted for publication July 20, 2020; available ahead of print July 23, 2020.

Address for reprints: Manan H. Desai, MD, Department of Cardiovascular Surgery, Children's National Heart Institute, Children's National Hospital, 111 Michigan Ave NW, Washington, DC 20010 (E-mail: mdesai2@childrensnational.org).

J Thorac Cardiovasc Surg 2021;161:1436-7

0022-5223/\$36.00

Copyright (c) 2020 by The American Association for Thoracic Surgery

https://doi.org/10.1016/j.jtcvs.2020.07.059
}

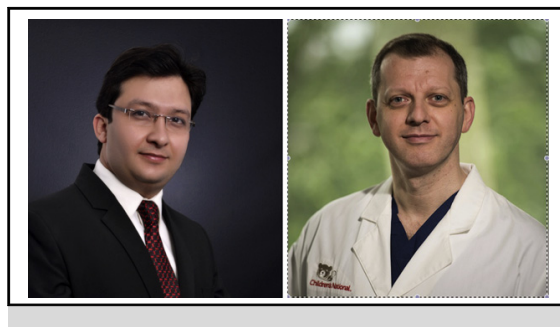

Manan H. Desai, MD, and Can Yerebakan, MD

CENTRAL MESSAGE

Early Fontan failure may be predicted early enough to improve outcomes of patients with single ventricle physiology.

actual postoperative CVP (correlation coefficient of 0.26 ; $P=.03$ ). An important caveat to this was that the calculated post-TCPC CVP overestimated the actual postoperative CVP by approximately $7 \mathrm{~mm} \mathrm{Hg}$. The correlation was even stronger in cases without a fenestration. In the second part of the study, they aimed to arrive at a calculated CVP that would predict Fontan takedown. The suggested threshold of predicted post-TCPC CVP of $33 \mathrm{~mm} \mathrm{Hg}$ or more was highly predictive of Fontan failure requiring surgical intervention (fenestration, takedown, transplant) or mortality.

The authors have to be commended for the work on patients palliated with single ventricle circulation. With advances in the field of perfusion, perioperative care, and better understanding of single ventricle physiology, the risk of early failure after staged palliation of single ventricles has been minimized. The risk of early Fontan failure in this series was $5 \%$, which is similar to other reports. The few cases of Fontan failure seen in clinical practice do not necessarily conform to conventional commandments, making prediction of Fontan failure challenging. Patients with normal pulmonary artery resistance and good single ventricular function may face Fontan failure. All patients in this study underwent preoperative CMR imaging 
before the TCPC. Quaila and colleagues ${ }^{4}$ devised a method based on CMR parameters to help physicians predict the risk of Fontan failure in the absence of classic harbingers. CMR is emerging adjuvant not only in pre-TCPC imaging but also in selected cases replacing conventional catheterization. ${ }^{5}$ However, many centers do not routinely perform CMR in the pre-Fontan workup. The variables used by the authors based on preoperative CMR to arrive at the predicted post-TCPC CVP are not available to those who do not routinely perform CMR before surgery. Thus, creating and validating similar formulae that predict post-TCPC CVP using cardiac catheterization would aid in surgical planning.

Engineers have recently come to the rescue of pediatric cardiac physicians in predicting postoperative hemodynamic variables using preoperative imaging, hemodynamic data, and state-of-art computational fluid dynamics. ${ }^{6}$ Recent studies on a small number of patients have shown a good correlation between predicted postoperative hemodynamics and calculated computational fluid dynamics data. ${ }^{7}$ Using these advanced computational fluid dynamics technologies to predict Fontan failure would be a desirable bench-to-bedside transition.

The prevention of a Fontan failure seems to be more important than its prediction. The lack of pulsatility is one factor that has been shown to result in endothelial dysfunction. ${ }^{8,9}$ This is one factor that could be producing Fontan failure despite normal Fontan pressures and ventricular function. In their retrospective comparing the long-term outcomes of the Fontan in patients with and without antegrade flow at the time of the Glenn procedure, Chen and colleagues ${ }^{10}$ found significantly better outcomes after pulsatile Glenn procedures, that is, a Glenn circulation with restricted antegrade pulmonary flow, which is still a topic of controversial discussion.
We congratulate the authors on their contribution to better understanding, predicting, and thus potentially preventing early Fontan failure after TCPC.

\section{References}

1. Fontan F, Mounicot F, Baudet E, Simonneau J, Gordo J, Gouffrant J. "Correction" of tricuspid atresia. 2 cases "corrected" using a new surgical technic. Ann Chir Thorac Cardiovasc. 1971;10:39.

2. Choussat A, Fontan F, Besse P, Vallot F, Chauve A, Bricaud H. Selection criteria for Fontan's procedure. In: Anderson RH, Shinebourne EA, eds. Paediatric Cardiology. New York: Churchill Livingstone, Edinburgh Scotland; 1978: 559-66.

3. Hosein RB, Clarke AJ, McGuirk SP, Griselli M, Stumper O, De Giovanni JV, et al. Factors influencing early and late outcome following the Fontan procedure in the current era. The 'Two Commandments'? Eur J Cardiothorac Surg. 2007; 31:344-53.

4. Quaila MA, Chan I, Sarnaa S, Hughes BS, Muthurangua V. A preoperative estimate of central venous pressure is associated with early Fontan failure. J Thorac Cardiovasc Surg. 2021;161:1426-34.

5. Fogel MA, Pawlowski TW, Whitehead KK, Harris MA, Keller MS, Glatz AC, et al. Cardiac magnetic resonance and the need for routine cardiac catheterization in single ventricle patients prior to Fontan: a comparison of 3 groups. J Am Coll Cardiol. 2012;60:1094

6. van Bakel TM, Lau KD, Hirsch-Romano J, Trimarchi S, Dorfman AL, Figueroa CA. Patient-specific modeling of hemodynamics: supporting surgical planning in a Fontan circulation correction. J Cardiovasc Transl Res. 2018;11: 145-55.

7. Baretta A, Corsini C, Marsden AL, Vignon-Clementel IE, Hsia T-Y, Dubini G, et al. Respiratory effects on hemodynamics in patient-specific CFD models of the Fontan circulation under exercise conditions. Eur J Mech B Fluids. 2012; 35:61-9.

8. Henaine R, Vergnat M, Bacha EA, Baudet B, Lambert V, Belli E, et al. Effects of lack of pulsatility on pulmonary endothelial function in the Fontan circulation. $J$ Thorac Cardiovasc Surg. 2013;146:522-9.

9. Latus H, Lederle A, Khalil M, Kerst G, Schranz D, Apitz C. Evaluation of pulmonary endothelial function in Fontan patients. J Thorac Cardiovasc Surg. 2019;158:523-31.

10. Chen Q, Tulloh R, Caputo M, Stoica S, Kia M, Parry AJ. Does the persistence of pulsatile antegrade pulmonary blood flow following bidirectional Glenn procedure affect long term outcome? Eur J Cardiothorac Surg. 2015;47: 154-8. 